\title{
Antidiabetic effect of Pterocarpus marsupium seed extract in gabapentin induced diabetic rats
}

\author{
Sivanageswararao Mekala ${ }^{1 *}$, Salum Seif Salum Mchenga ${ }^{2}$, Saravanan R. ${ }^{3}$
}

${ }^{1}$ Department of Pharmacology and Head of Allied Health Sciences, ${ }^{2}$ Department of Pathology, School of Health and Medical Sciences, The State University of Zanzibar, Tanzania

${ }^{3}$ Department of Pharmacology, RVS Dental College and Hospital, Coimbatore, Tamilnadu, India

Received: 02 September 2019

Revised: 10 October 2019

Accepted: 22 January 2020

\section{*Correspondence:}

Dr. Sivanageswararao Mekala,

Email: sivanageshmekala@yahoo.com

Copyright: (c) the author(s), publisher and licensee Medip Academy. This is an open-access article distributed under the terms of the Creative Commons Attribution Non-Commercial License, which permits unrestricted non-commercial use, distribution, and reproduction in any medium, provided the original work is properly cited.

\begin{abstract}
Background: Type 2 diabetes mellitus is the most common type of diabetes. Diabetes mellitus is a leading cause of morbidity and mortality among Indian population and all over the world with more than hundreds of millions of patients worldwide. Pterocarpus marsupium is a medicinal plant used in Ayurvedic system of medicine to control blood sugar and strong antidiabetic. The purpose of this study was to assess the hypoglycemic effect of the ethanolic extract of Pterocarpus marsupium seeds in diabetic rats.

Methods: The present work was designed to evaluate the anti-hyperglycaemic activity of Pterocarpus marsupium seed extract $(100 \mathrm{mg} / \mathrm{kg}$ and $200 \mathrm{mg} / \mathrm{kg})$ on gabapentin induced hyperglycaemia in wistar albino rats. Blood glucose level, serum triglycerides, total cholesterol, HDL cholesterol and LDL cholesterol were evaluated in gabapentin induced diabetic rats. The results of the test drug were compared with the standard drug.

Results: Ethanolic seed extract of Pterocarpus marsupium at $100 \mathrm{mg} / \mathrm{kg}$ and $200 \mathrm{mg} / \mathrm{kg}$ had significantly reduced the blood glucose level compared to disease control rats on day 1, 7, 14 and 21. Pterocarpus marsupium shows significant decrease in triglycerides levels, serum cholesterol levels, LDL levels and increased HDL levels, total protein levels compared to the disease control group.

Conclusions: In conclusion, the present study shows that the ethanolic seed extract of Pterocarpus marsupium has potential antidiabetic action in gabapentin induced diabetic rats and the effect was found to be more similar to the standard drug metformin.
\end{abstract}

Keywords: Diabetes mellitus, Gabapentin, Metformin, Pterocarpus marsupium

\section{INTRODUCTION}

Diabetes mellitus is a metabolic disorder initially characterized by a loss of glucose homeostasis with disturbances of carbohydrate, fat and protein metabolism resulting from defects in insulin secretion, insulin action, or both. If the glucose level in the blood remains high over a long period of time, this can result in long-term damage to organs, such as the kidneys, liver, eyes, nerves, heart and blood vessels. Diabetes contains a number of chronic complications like nephropathy, neuropathy, retinopathy and cardiovascular diseases. The individual with diabetes has a 20 -fold increase in the risk of renal failure, a 25 -fold increase in the risk of blindness, a 20 -fold increase in the risk of amputation and a 2 to6 fold increased risk of coronary heart disease and ischemic brain damage. ${ }^{1}$

The heartwood of Pterocarpus marsupium is used in the treatment of inflammation and reported to have medicinal 
importance in the management of diabetes since long. ${ }^{2}$ The flavonoids and phenolic contents present in the tree viz., marsupin, pterosupin, and liquiritigenin are reported to have antihyperglycemic and antihyperlipidemic activities. $^{2-4}$ Pterocarpus marsupium extracts may serve as a potential source of natural antioxidant as well as for the treatment of diabetes. ${ }^{5-7}$

Serum lipid levels in rats with hyperlipidemia induced by diet as well as by triton were determined after oral administration of EtOAc extract of Pterocarpus marsupium heartwood and its flavonoid constituents, marsupsin, pterosupin, and liquiritigenin. Administration of EtOAc extract for 14 consecutive days produced a significant reduction of serum triglyceride, total cholesterol, and LDL and VLDL cholesterol levels without any significant effect on the level of HDL cholesterol. $^{8}$

The ethanolic extract (100 mg/kg body weight) when given to streptozotocin (STZ) induced diabetic rats for 10 consecutive days declined blood glucose, improved oral glucose tolerance test and increased their serum insulin levels. The ethanolic extract also showed marked improvement on oral glucose tolerance on high fat-low dosed STZ-induced diabetic rats and neonatally STZ treated rats. The ethanolic extract of Pterocarpus marsupium also showed marked anti-dyslipidemic effects on high fat diet fed Syrian golden hamsters. ${ }^{9}$

Pterocarpus marsupium has also been documented to help in regeneration of pancreatic $\beta$-cells. ${ }^{10,11}$ The active antidiabetic ingredients in the aqueous extract has been identified as (-) epicatechin, a benzopyran which on administration to alloxan-induced diabetic rats increased insulin secretion and number of islets in the pancreas. Insulin like activity of (-) epicatechin has been reported. ${ }^{12}$ Heartwood of Pterocarpus marsupium has also been tested clinically and found effective in non-insulin dependent diabetes mellitus patients (type 2DM). ${ }^{13}$

The purpose of this experimental study is to investigate the antidiabetic activity of Pterocarpus marsupium seed extract on gabapentin induced diabetes. The anti-diabetic activity was evaluated by measuring the blood glucose levels, lipid profile and histopathological examination.

\section{METHODS}

Male wistar albino rats weighing 200 - 250 gm were used in the study. They were housed and maintained under standard condition in the central animal house. The rats were kept in clean, clear polypropylene cages in groups of three in each cage maintained at 10 hours of light and 14 hours dark cycle. They were maintained under standard environmental conditions and fed with standard pellet diet (laboratory animal feeds) and water ad libitum.

\section{Identification and collection}

Pterocarpus marsupium belongs to the family Fabaceae, class Magnoliopsida. Its common names are Indian kino tree, Malabar kino tree. Pterocarpus marsupium Roxb is a large deciduous tree commonly found in hilly region of India. The plant is distributed in India (Andhra Pradesh, Bihar, Gujarat, Kerala, Madhya Pradesh, Maharashtra, Karnataka, Orissa, Tamilnadu and Uttar Pradesh), Nepal, SriLanka. Flowering and fruiting are observed during April-July and August-October. ${ }^{14}$

The leaves are simple, alternate on long petioles, cordate withs even shallow lobes and variously serrated margins, very hairy on the abaxial surface, acute, deep green and about $7-15 \mathrm{~cm}$ in diameter. They are herbaceous but rigid, becoming rough on both sides, 60-200 $\mathrm{mm}$ long and $40-150 \mathrm{~mm}$ broad, sometimes unlobed, but usually deeply 3-lobed with the segments again lobed or doubly lobed, whereas the central lobe is much the largest. The leaf stalks are hairy and $150 \mathrm{~mm}$ long. Tendrils are simple and spiral. ${ }^{15}$

Male and female flowers grow on the same plant i.e., monoecious with the flower stalk up to $40 \mathrm{~mm}$ long hairy. Both have yellow petals, five in number, and sepals, also five in number and greenish in color. The fruits are globular with shallow grooves, about $14-20 \mathrm{~cm}$ long. Fruit is legume indehiscent, orbicular, compressed, broadly hardened winged around margin, usually single seeded, seeds subreniform, hilum small. The flesh is sweet, delicately flavoured, and juicy in nature. The corolla is green or green veined outside and inside the colour is white to pale or bright yellow and diameter is up to $30 \mathrm{~mm} .{ }^{16}$ The seeds are small, obovate to elliptical, light brown or black in colour, and smooth, between 0.5 $1.5 \mathrm{~cm} \times 0.5-1 \mathrm{~cm}$ long and $0.2-0.3 \mathrm{~cm} .{ }^{17}$

\section{Extraction of Pterocarpus marsupium}

The seeds are collected, washed, shade dried, coarsely powdered and then passed through 40 mesh sieves. The coarsely powdered materials were subjected to successive extraction with petroleum ether, ethyl acetate, and ethanol for $72 \mathrm{hrs}$. The extract solutions obtained were collected separately and the collected extract was concentrated under reduced pressure $\left(<45^{\circ} \mathrm{C}\right)$ using a vacuum pump for complete removal of the solvent. Pure organic part of the sample thus prepared and was stored at $4-5^{\circ} \mathrm{C}$ until used.

The yield of ethanolic extract was collected and weighed. Acute toxicity study was done by oral administration of $2000 \mathrm{mg} / \mathrm{kg}$ body weight in rats. There were no clinical symptoms or mortality and no significant abnormalities were noted during post-mortem examinations. Pterocarpus marsupium was non-toxic to rats even at high dose. 


\section{Induction of diabetes in rats}

After overnight fasting, experimental diabetes was induced by single intra-peritoneal injection of gabapentin $(150 \mathrm{mg} / \mathrm{kg})$ in rats. The gabapentin was freshly prepared by dissolving $150 \mathrm{mg}$ of gabapentin in normal saline solution. The animals were allowed to drink $20 \%$ glucose solution to overcome the drug induced hypoglycemia. 48 hours after injection of gabapentin, fasting plasma blood glucose was estimated. Animals with plasma glucose levels of $>250 \mathrm{mg} / \mathrm{dl}$ were selected for anti-diabetic activity.

\section{Experimental design}

The study was carried out after obtaining approval by the Institutional Animals Ethics Committee (IAEC). Thirty rats were used in this study. They were divided into five groups of six animals each. The vehicle/drug was administered for a period 21 days from the day of induction of diabetes. Drug/vehicle was administered orally (p.o.) under aseptic conditions. The treatment schedule was as follows:

- Group I- Normal control group, normal rats were administered with normal saline $(10 \mathrm{ml} / \mathrm{kg})$ and no drug treatment.

- Group II- Disease control group, diabetic rats were administered with normal saline $(10 \mathrm{ml} / \mathrm{kg})$ and no drug treatment. Experimental diabetes was induced by single intra-peritoneal injection of gabapentin (150 $\mathrm{mg} / \mathrm{kg}$ ).

- Group III- Diabetic rats were administered with standard drug metformin $(150 \mathrm{mg} / \mathrm{kg}$, p.o.).

- Group IV- Diabetic rats were administered with Pterocarpus marsupium (100 mg/kg, p.o.).

- Group V- Diabetic rats were administered with Pterocarpus marsupium (200 mg/kg, p.o.). Drug/vehicle was administered to the rats for 21 days.

\section{Collection of blood}

The blood samples were collected on 1st, 7th, 14th and 21 st day from tail and retro-orbital venous plexus of rats by giving anesthesia using a glass capillary tube after a fast of $12 \mathrm{hrs}$ and the blood was centrifuged to get serum. The serum was used for biochemical estimation of blood glucose, triglycerides, serum cholesterol, HDL cholesterol, LDL cholesterol, total proteins. Blood glucose levels were estimated by using glucose oxidaseperoxidase (GOD-POD) kit. On 21st day all the animals were sacrificed after collection of blood samples and the pancreas was collected. The isolated pancreas was used for study the anti-oxidant parameters.

\section{Estimation of blood glucose $e^{18}$}

Blood glucose was estimated by using glucose kit obtained from Span Diagnostics using GOD-POD method. GOD oxidizes glucose to glucoronic acid and
$\mathrm{H}_{2} \mathrm{O}_{2}$. In presence of enzyme peroxidase, released $\mathrm{H}_{2} \mathrm{O}_{2}$ is combined with phenol and 4-aminoantipyrine (4-AAP) and forms coloured quinoneimine dye. By using colorimeter absorbance of dye is measured at $505 \mathrm{~nm}$ and is directly proportional to glucose concentration in the sample.

\section{Estimation of triglycerides (GPO-POD method $)^{19}$}

Triglycerides (TGL) were estimated by using the kit obtained from Span Diagnostics. TGL were hydrolysed by lipoprotein lipase (LPL) to produce glycerol and free fatty acid (FFA). In presence of glycerol kinase (GK), adenosine triphosphate (ATP) phosporylates glycerol to produce glycerol-3-phosphate and adenosine diphosphate (ADP). Glycerol 3-phosphate is further oxidized by glycerol 3-phosphate oxidase (GPO) to produce dihydroxy acetone phosphate (DAP) and H2O2. In presence of peroxidase (POD), hydrogen peroxide couples with 4-amino antipyrine (4-AAP) and 4-Chloro phenol to produce red quinoneimine dye. Absorbance of coloured dye is measured at $505 \mathrm{~nm}$ and is proportional to TGL concentration in the sample.

\section{Estimation of total cholesterol (Chod-Pod/ Phosphotungstate method) ${ }^{19}$}

Pipette the samples and the reagent into 3 test tubes labelled blank (B), standard (S), and Total cholesterol (Tc). Mix well and incubate for $5 \mathrm{~min}$ at $37^{\circ} \mathrm{C}$ or $10 \mathrm{~min}$ at room temperature. Read the absorbance of standard (S), total cholesterol (Tc) against blank at $505 \mathrm{~nm}$. Absorbance of quinoneimine was measured at $505 \mathrm{~nm}$ which is proportional to cholesterol concentration. Total cholesterol $($ in $\mathrm{mg} / \mathrm{dl})=($ Abs. of test/Abs. of standard $) \times$ 200. Cholesterol concentration $=$ Concentration $(\mathrm{mg} / \mathrm{dl}) \times$ 0.0259

\section{Estimation of HDL}

Pipette out serum/plasma $0.2 \mathrm{ml}$ and precipitating reagent $0.3 \mathrm{ml}$ into the centrifuge tube. Mix well and allow standing at room temperature for $5 \mathrm{~min}$. Centrifuge at $3000 \mathrm{rpm}$ for $10 \mathrm{~min}$ to get a clear supernatant. If supernatant is not clear (high TGL level) dilute the sample 1:1 normal saline and multiply the result with 2 . Pipette into 3 test tubes labelled blank (B), standard (S), HDL cholesterol (TH). Mix well and incubate for $5 \mathrm{~min}$ at $37{ }^{\circ} \mathrm{C}$ or $10 \mathrm{~min}$ at room temperature. Read the absorbance of standard (S), HDL cholesterol (TH) against blank at $505 \mathrm{~nm}$. HDL cholesterol was calculated using the formula. HDL Cholesterol $(\mathrm{mg} / \mathrm{dl})=$ Absorbance of test/ Absorbance of standard $\times 50$.

\section{Estimation of total protein (Biuret method) $)^{20}$}

Proteins bind with copper ions in the alkaline medium of biuret reagent and reduce a purple colored complex, whose absorbance is proportional to the protein concentration. Pipette out the samples and reagents into 
clean dry test tubes labelled blank (B), standard (S) and test (T). Mix well and incubate at $37^{\circ} \mathrm{C}$ for $10 \mathrm{~min}$. Measure the absorbance of standard (S) and test (T) against blank (B) on a spectrophotometer at $555 \mathrm{~nm}$. Total protein $(\mathrm{gm} \%)=$ Absorbance of test $/$ Absorbance of standard $\times 6.5$.

\section{Histopathology studies}

Light microscopy: the pancreas was removed, washed immediately with saline and then fixed in $10 \%$ buffered formalin. The Pancreas stored in $10 \%$ buffered formalin, were embedded in paraffin, sections cut at $5 \mu \mathrm{m}$ and stained with hematoxylin and eosin. The hematoxylin and eosin stained sections were then examined under a light microscope for histological changes.

\section{Statistical analysis}

The mean value \pm SEM will be calculated for each parameter. Data analysis was carried out using one-way analysis of variance (ANOVA) followed by Dunnett's multiple comparison tests by using graph pad prism version 5.01.

\section{RESULTS}

When the rats were sacrificed, the abdominal cavity was examined macroscopically before and after removing the pancreas for any abnormality. It was observed that there was no visible abnormality seen in pancreas and other viscera in the abdominal cavity in control group and the test group of rats.

Rats treated with Pterocarpus marsupium $100 \mathrm{mg} / \mathrm{kg}$ and $200 \mathrm{mg} / \mathrm{kg}$ has significantly reduced blood sugar compared to disease control group on 1st day, 7th day, 14th day, 21st day in gabapentin induced diabetes in epileptic rats. The fall in blood sugar level in rats treated with Pterocarpus marsupium $100 \mathrm{mg} / \mathrm{kg}(104.4 \pm 1.05)$ and $200 \mathrm{mg} / \mathrm{kg}(101.6 \pm 1.87)$ was comparable to the results produced by the standard drug metformin

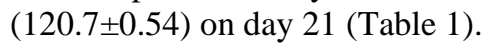

Table 1: Effect of extract of Pterocarpus marsupium seeds on plasma glucose levels in gabapentin induced diabetic rats.

\begin{tabular}{|llll|l|}
\hline Group & $\begin{array}{l}\text { Glucose levels } \\
\text { (mg/dl) } \\
1^{\text {st }} \text { day }\end{array}$ & $\begin{array}{l}\text { Glucose levels } \\
\text { (mg/dl) } \\
\text { 7th day }\end{array}$ & $\begin{array}{l}\text { Glucose levels } \\
\text { (mg/dl) } \\
\text { 14th day }\end{array}$ & $\begin{array}{l}\text { Glucose } \\
\text { levels(mg/dl) } \\
\mathbf{2 1}^{\text {st }} \text { day }\end{array}$ \\
\hline Normal control & $113.4 \pm 0.68$ & $120.1 \pm 1.02$ & $105.1 \pm 1.02$ & $110.1 \pm 1.02$ \\
\hline Disease control & $289.5 \pm 1.70$ & $293.7 \pm 0.34$ & $274.4 \pm 0.68$ & $288.7 \pm 0.85$ \\
\hline Standard (metformin) & $161.1 \pm 0.51^{*}$ & $141.1 \pm 0.51^{*}$ & $126.8 \pm 1.36^{*}$ & $120.7 \pm 0.54^{*}$ \\
\hline P. marsupium $\mathbf{( 1 0 0 ~} \mathbf{~ m g / k g )}$ & $215.4 \pm 1.43^{*}$ & $161.4 \pm 0.74^{*}$ & $118.8 \pm 1.83^{*}$ & $104.4 \pm 1.05^{*}$ \\
\hline P. marsupium $\mathbf{( 2 0 0} \mathbf{~ m g / k g )}$ & $198.1 \pm 0.91^{*}$ & $152.8 \pm 1.4^{*}$ & $111.4 \pm 1.75^{*}$ & $101.6 \pm 1.87^{*}$ \\
\hline
\end{tabular}

Values are expressed as mean \pm SEM, Oneway ANOVA followed by Dunnet's test. * $\mathrm{p}<0.001$ when compared with disease control group.

Table 2: Effect of extract of Pterocarpus marsupium seeds on biochemical parameters in serum of gabapentin induced diabetic rats.

\begin{tabular}{|c|c|c|c|c|c|}
\hline Groups & TG & Cholesterol & HDL & LDL & Total protein \\
\hline Normal control & $79.47 \pm 1.95$ & $131.1 \pm 1.02$ & $55.83 \pm 0.78$ & $71.04 \pm 0.88$ & $6.97 \pm 0.03$ \\
\hline Disease control & $169.15 \pm 1.23$ & $247.5 \pm 0.51$ & $36.41 \pm 0.68$ & $188.13 \pm 0.68$ & $3.79 \pm 0.11$ \\
\hline Standard (metformin) & $105.48 \pm 0.98 *$ & $153.1 \pm 1.02 * *$ & $48.32 \pm 0.71 *$ & $92.51 \pm 0.33 * *$ & $5.74 \pm 0.08 * *$ \\
\hline P. marsupium $(100 \mathrm{mg} / \mathrm{kg})$ & $91.83 \pm 1.36^{* *}$ & $136.4 \pm 1.98 * *$ & $48.12 \pm 1.02 *$ & $84.53 \pm 0.42 * *$ & $6.63 \pm 0.30 * *$ \\
\hline P. marsupium $(200 \mathrm{mg} / \mathrm{kg})$ & $83.35 \pm 1.41 * *$ & $127.6 \pm 1.19 * *$ & $52.36 \pm 1.44 * *$ & $79.53 \pm 1.00 * *$ & $7.84 \pm 0.11 * *$ \\
\hline
\end{tabular}

Values are expressed as mean \pm SEM, Oneway ANOVA followed by Dunnet's test. *p<0.05, and **p<0.001 when compared with disease control group.

Rats treated with gabapentin showed a significant increase in the triglyceride's levels compared to control group. Standard drug metformin improved the cholesterol levels comparable to the control group. Rats treated with Pterocarpus marsupium $100 \mathrm{mg} / \mathrm{kg}$ and $200 \mathrm{mg} / \mathrm{kg}$ significantly decreased triglycerides levels, serum cholesterol levels, LDL levels and increased HDL levels, total protein levels compared to the disease control group. The improvement in lipid profile was comparable and slightly higher than the standard drug metformin (Table 2).

\section{Histopathological reports of gabapentin induced diabetic rats}

In the histopathological studies, the normal control groups of rats (Figure 1) have normal islets of Langerhans, acinar cells and $\beta$ cells. In disease control group (Figure 2) shows degenaration and necrosis of pancreatic cells; extensive damage to the islets of Langerhans and damage of intralobular ducts were observed. Rats treated with standard drug (Figure 3 ) shows normal pancreatic $\beta$ cells, normal islets of Langerhans. Rats treated with seed extract 
of Pterocarpus marsupium (Figure 4 and 5) shows the regeneration of pancreatic $\beta$ cells with normal islets cells, normal acinar cells and normal intra lobular ducts.

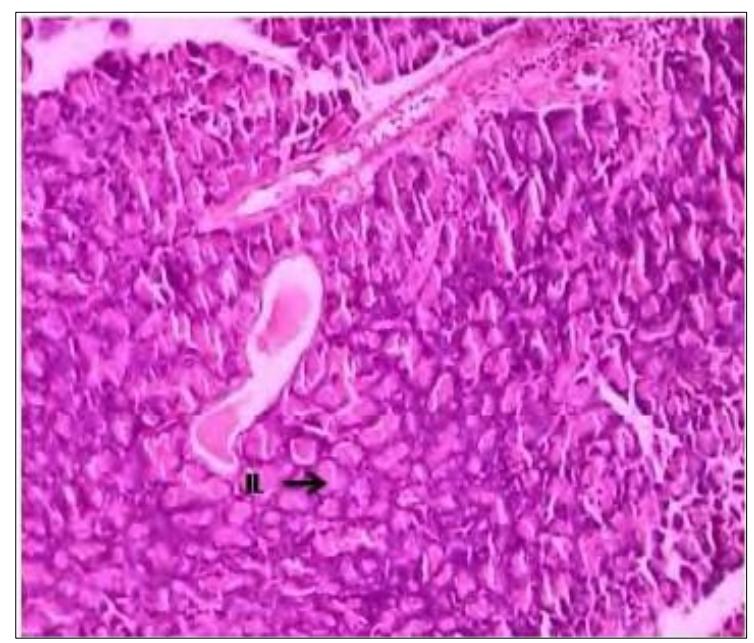

Figure 1: Pancreas of normal control rat.

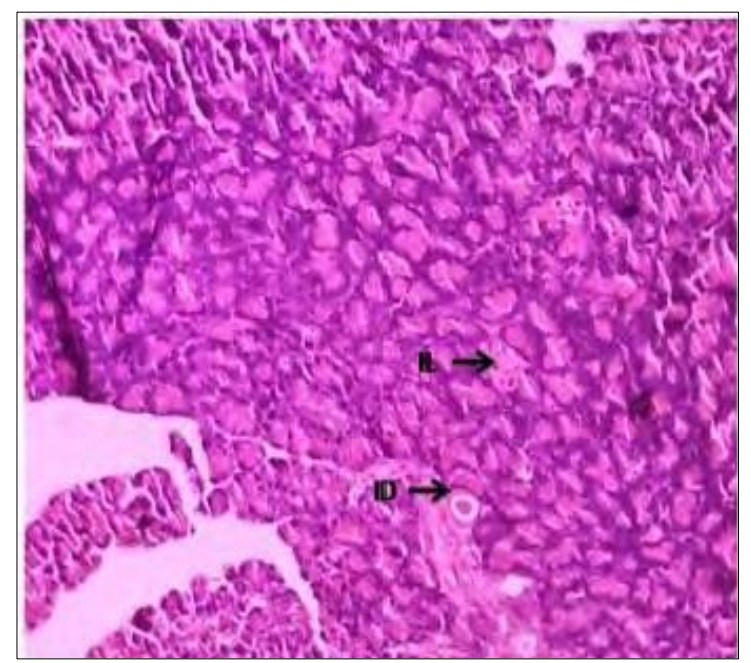

Figure 2: Pancreas of disease control rat.

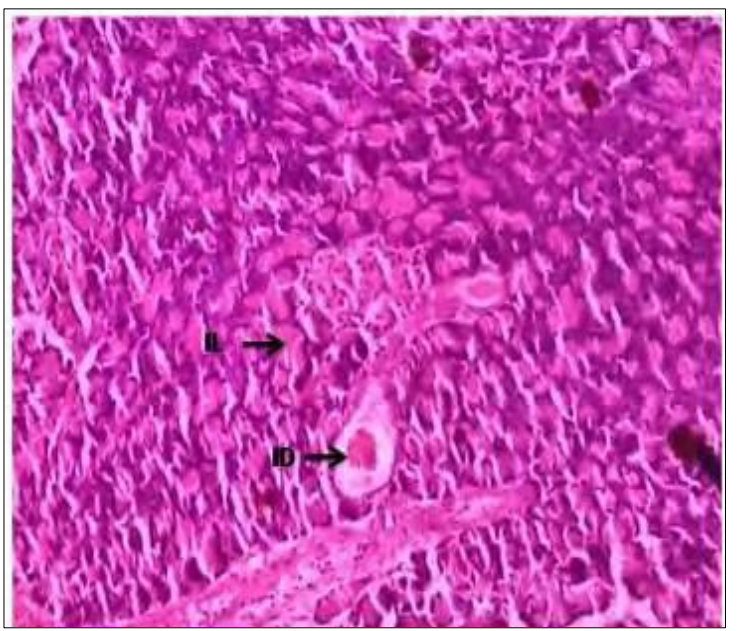

Figure 3: Pancreas of standard rat.

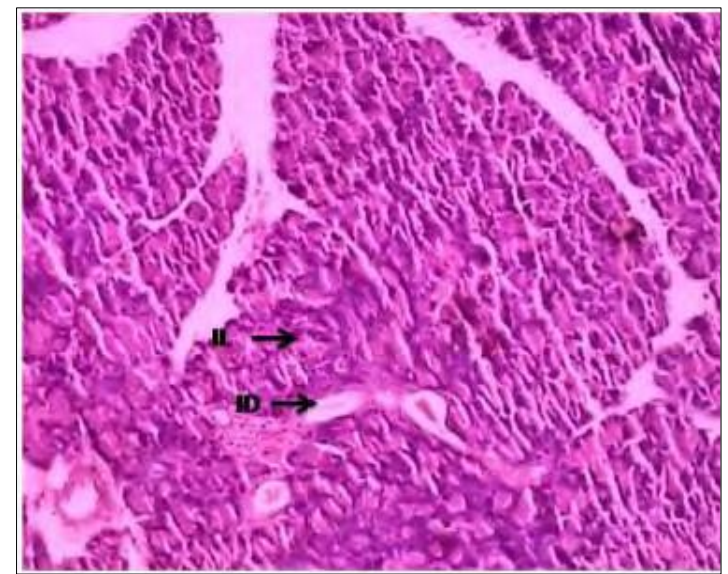

Figure 4: Pancreas of treatment rat $(100 \mathrm{mg} / \mathrm{kg})$.

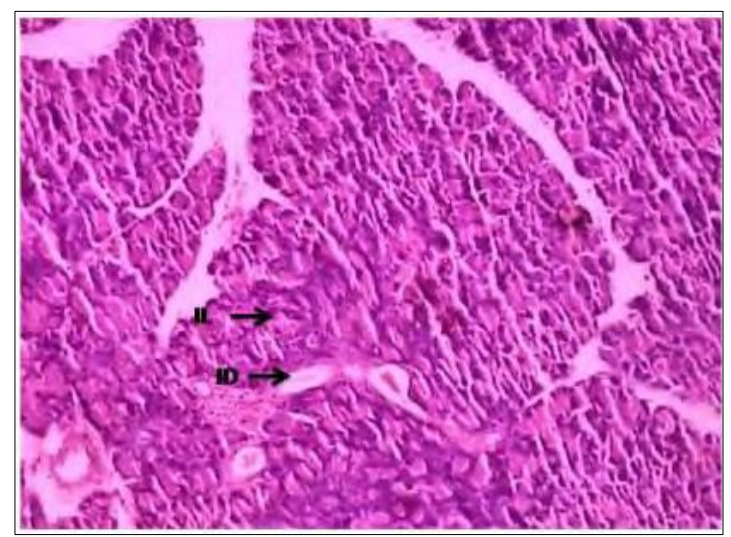

Figure 5: Pancreas of treatment rat $(200 \mathrm{mg} / \mathrm{kg})$.

\section{DISCUSSION}

Diabetes mellitus is the one of the major metabolic disorder which affecting the three fourth of the world's population. It is fourth leading causes of death in the world. Insulin dependent diabetes is characterized by juvenile onset and insulin deficiency. Non-insulin dependent diabetes is characterized by mature onset and varying basal insulin levels. There are several reasons for the diabetes, major reason is inheritance. This diabetes can cause micro and macro vascular complications like renal failure, coronary artery disorders cerebrovascular disease, neurological complications, blindness, obesity, and hyperglycaemia.

There are different chemicals agents capable of producing the alterations related to the diabetic condition. In this present work gabapentin was used as inducing drugs. Gabapentin is used in the treatment of epileptic seizures. The induction of diabetes using gabapentin is referred as drug induced diabetes. Administration of gabapentin significantly increased the level of glucose when compared to control. The present study was designed to evaluate the hypoglycemic and hypolipidemic activity of seed extract of Pterocarpus marsupium in gabapentin drug induced diabetes. This ethanolic seeds extract 
contains the compounds like carbohydrates, flavonoids, and alkaloids.

Administration of gabapentin significantly increases the glucose levels when compared to normal control group, which account for cytotoxic action of gabapentin. Metformin was taken as standard. The seed extract of Pterocarpus marsupium in lower dose $(100 \mathrm{mg} / \mathrm{kg})$, higher dose $(200 \mathrm{mg} / \mathrm{kg})$ were taken. The induced hyperglycaemia was present till end of the experiment which was compared with the normal group by observing the blood glucose levels. Induced diabetes was decreased by the protective mechanism of standard drug. The test drug at $100 \mathrm{mg} / \mathrm{kg}$ and $200 \mathrm{mg} / \mathrm{kg}$ had decreased levels of glucose $104.4 \pm 1.05$ and $101.6 \pm 1.87$ respectively when compare to disease control group. Similar hypoglycaemic activity was observed in studies which used Pterocarpus marsupium heartwood, roots and bark. ${ }^{21-24}$ But the test drug does not show more protective mechanism when compare with the standard drug in gabapentin induced diabetic models.

The test drug shows reduced levels of total cholesterol, triglycerides, LDL to a significant level when compared to the disease control group. HDL and Total protein levels were increased with the test drug when compare to disease control group. Test drug at high dose $(200 \mathrm{mg} / \mathrm{kg})$ showed significant reduction of $\mathrm{TG}$, total cholesterol, LDL levels in gabapentin induced diabetes models.

In the histopathological studies the pancreas of normal control group of rats showed normal islets of Langerhans, normal acinar cells and normal $\beta$ cells. In the disease control group degeneration and necrosis of pancreatic cells, extensive damage to the islets of Langerhans and damage of intralobular ducts were observed. Seed extract of Pterocarpus marsupium showed the regeneration of pancreatic $\beta$ cells with normal islets cells, normal acinar cells and normal intra lobular ducts. Metformin treated diabetic rats also shows normal pancreatic $\beta$ cells, normal islets of Langerhans. So, the seed extract of Pterocarpus marsupium shows anti diabetic activity.

\section{CONCLUSION}

In the present study, Pterocarpus marsupium at 100 $\mathrm{mg} / \mathrm{kg}$ and $200 \mathrm{mg} / \mathrm{kg}$ has significantly reduced the blood glucose level on all the days of blood sampling. Pterocarpus marsupium $100 \mathrm{mg} / \mathrm{kg}$ and $200 \mathrm{mg} / \mathrm{kg}$ has significantly reduced the total cholesterol, triglycerides and LDL levels and significantly increased the HDL level compared to disease control group of rats. In conclusion, the present study shows that the ethanolic seed extract of Pterocarpus marsupium has potential antidiabetic action in gabapentin induced diabetic rats and the effect was found to be more similar to the reference drug metformin.

\section{ACKNOWLEDGEMENTS}

Authors would like to thank Department of Pharmacology School of Health and Medical Sciences, The State University of Zanzibar, Tanzania.

\section{Funding: No funding sources}

Conflict of interest: None declared

Ethical approval: The study was approved by the Institutional Ethics Committee

\section{REFERENCES}

1. Kirkham S, Akilen R, Sharma S, Tsiami A. The potential of cinnamon to reduce blood glucose levels in patients with type 2 diabetes and insulin resistance. Diabetes, Obesity Metab. 2009;11(12):1100-3.

2. Patil UH, Dattatraya KG. Pterocarpus marsupium: a valuable medicinal plant in diabetes management. Int J App Bio Pharm Tech. 2011;2:6-13.

3. Waghmare AS, Waghmare PD, Grampurohit ND, Gadhave MV. Free radical scavenging activity of methanolic and aqueous extract of Pterocarpus marsupium heartwood by DPPH method. J Sci Res Phar. 2012;1:89-91.

4. Hilal A, Kalyanaraman R. Pharmacology of Pterocarpus marsupium Roxb. Med Plant Res. 2015;5:1-6.

5. Vats V, Grover JK, Rathi SS. Evaluation of antihyperglycemic and hypoglycemic effect of Trigonellafoenum-graecum Linn, Ocimum sanctum Linn and Pterocarpus marsupium Linn in normal and alloxanizeddiabetic rats. J Ethnopharmacol. 2002;79:95-100.

6. Karanjit N, Shrestha UK, Ranjitkar RR. A study on hypoglycemic properties of Pterocarpus marsupiumRoxb. Bullet Dept Plant Res. 2008;30:97101.

7. Manickam M, Ramanathan M, Jahromi MA, Chansouria JP, Ray AB. Antihyperglycemic activity of phenolics from Pterocarpus marsupium. J Nat Prod. 1997;60:609-10.

8. Jahromi MA, Ray AB. Antihyperlipidemic effect of flavonoids from Pterocarpus marsupium. J Nat Prod. 1993;56(7):989-94.

9. Mishra A, Srivastava R, Srivastava SP, Gautam S, Tamrakar AK, Maurya R, et al. Antidiabetic activity of heart wood of Pterocarpus marsupiumRoxb. and analysis of phytoconstituents. Ind J Experiment Biol. 2013;51:363-74.

10. Chakravarthy BK, Gupta S, Gambhir SS, Gode KD. Pancreatic beta-cell regeneration- A novalantidiabetic mechanism of Pterocarpus marsupium, Roxb., Indian J Pharmac. 1980;12:123-4.

11. Ahmad F, Khalid P, Khan MM, Rastogi AK, Kidwai JR. Insulin like activity in (-)-epicatechin. Acta Diabetologica Lat. 1989;26:291.

12. Chakravarthy BK, Gupta S, Gambhir SS, Gode KD. The prophylactic action of $(-)$-epicatechin against 
alloxan induced diabetes in rats. Life Sci. 1981;29(20):2043-7.

13. Philip S. Flexible dose open trial of Vijayasar in cases of newly-diagnosed non-insulin-dependent diabetes mellitus. Indian Council of Medical Research (ICMR), Collaborating Centres, New Delhi. Ind J Med Res. 1998;108:24-9.

14. Langham DR. Growth and development of sesame. Sesaco Corp. 2008: 329.

15. Zohary D, Hopf M, Weiss M. Domestication of Plants in the Old World: The Origin and Spread of Cultivated Plants in West Asia, Europe, and the Nile Valley. Oxford University Press. 2000

16. Oplinger ES, Putnam DH, Kaminski AR, Hanson CV, Oelke EA, Schulte EE, et al. Sesame. Available at: https://hort.purdue.edu/newcrop/afcm/sesame. html. Accessed on 02 December 1997.

17. Noon DD. Sesame Oil Benefits Blood Pressure Cooking Oil Switch May Be High Blood Pressure Treatment. Inter-Am Soc Hypertension. 2003.

18. Srikanth M, Rao GV, Rao KS. Modified assay procedure for the estimation of serum glucose using microwell reader. Ind $\mathbf{J}$ Clini Biochem. 2004;19(1):34-5.

19. Penumarthy S, Penmetsa GS, Mannem S. Assessment of serum levels of triglycerides, total cholesterol, high-density lipoprotein cholesterol, and low-density lipoprotein cholesterol in periodontitis patients. J Indian Soc Periodontol. 2013;17(1):30-5.
20. George RK, Kingsley R. Determination of serum total protein, albumin, and globulin by the biuret reaction. J Biol. Chem. 1939;131:197-200.

21. Mishra A, Srivastava R, Srivastava SP, Gautam S, Tamrakar AK, Maurya R, Srivastava AK. Antidiabetic activity of heart wood of Pterocarpus marsupium Roxb and analysis of phytoconstituents. Indian J Exp Biol. 2013;51(5):363-74.

22. Abhishek N, Hegde K, Chaithra Amin B, Kumar A. Evaluation of antidiabetic activity of ethanolic extract of roots of Pterocarpus marsupium in streptozotocin induced diabetic rats. $\mathrm{J}$ Pharmaceut Biol Sci. 2017;5(4):145-9.

23. Maruthupandian A, Mohan VR. Antidiabetic, Antihyperlipidaemic and Antioxidant activity of Pterocarpus marsupium Roxb. in alloxan induced diabetic rats. Inter $\mathbf{J}$ Pharm Tech Res. 2011;3(3):1681-87.

24. Perera HK. Antidiabetic effects of Pterocarpus marsupium (Gammalu). Europ J Med Plants. 2016:13(4):1-14.

Cite this article as: Mekala S, Mchenga SSS, Saravanan R. Antidiabetic effect of Pterocarpus marsupium seed extract in gabapentin induced diabetic rats. Int J Basic Clin Pharmacol 2020;9:371-7. 